\title{
Prognostic factors for return to work after a first compensated episode of back pain
}

\author{
Claire Infante-Rivard, Monique Lortie
}

\begin{abstract}
Objectives-To determine which factors measured at baseline and during the course of treatment influence time to return to work after a first compensated episode of back pain.
\end{abstract}

Methods-The design is a treatment inception cohort including 305 compensated workers out of $\mathbf{4 0 2}$ eligible ones presenting at two rehabilitation centres for conventional treatment. Crude and adjusted rate ratios (RRs) along with $95 \%$ confidence intervals ( $95 \%$ CIs) were estimated with the Cox's proportional hazards regression.

Results $-50 \%$ of workers had not returned to work after 112 days of follow up, and $11.3 \%$ still had not after 270 days. At the end of the study period (maximum follow up time was 1228 days), 230 workers $(75.4 \%)$ had returned to work, $6 \cdot 5 \%$ had not, and a similar percentage had retired, gone into vocational training, or returned to school. In the final model stratified for radiating pain during treatment, which was an important prognostic variable, workers between 21 to 30 years of age had a greater chance of returning to work (RR (95\% CI) $1.43(1.04$ to 1.98$)$ ) than those $\geqslant 30$. The other factors associated with a greater chance of returning to work were: a diagnosis of sprain or pain $v$ a diagnosis of intervertebral disc disorder $\mathbf{( 2 \cdot 2 0}$ $(1 \cdot 23-3 \cdot 91)),<30$ days of waiting between the accident and the beginning of treatment (1.30 (0.96 to 1.77)), a good flexion at baseline (1.52 (1.04 to 2.23$))$, absence of neurological symptoms during treatment $(1.40(0.98-2 \cdot 00)),>24$ months of employment in the industry $(1.49(1.10$ to $2 \cdot 03))$, working for a public industry $v$ a private one $(1.63(1 \cdot 21$ to $2 \cdot 19))$, and the ability to take unscheduled breaks $(1.45)(1.06$ to 1.97)).

Conclusions-Even with a first episode of back pain, time to return to work is long and the proportion not returning is high. Return to work as expected is influenced by disease and host characteristics but also by social and work factors. Reinstatement programmes should account for all these factors.

(Occup Environ Med 1996;53:488-494)

Keywords: low back pain; return to work; prognosis
Among workers in some industrialised nations, absenteeism for low back pain has reached epidemic proportions. ${ }^{1}$ In the United States, direct costs are extremely high for medical care of low back pain as are indirect costs due to absenteeism. ${ }^{2}$ Although work recovery from an acute episode is rapid for most patients, between $5 \%$ and $10 \%$ of patients with compensated back pain are disabled for more than three months ${ }^{23}$ and account for $70 \%$ to $90 \%$ of the costs. ${ }^{4}$ These data arise from administrative files where all compensated workers are registered, including those with a single day of compensation. On the other hand, from reported cohort studies of workers actively followed up over varied periods of time and who have usually gone into some form of rehabilitative treatment, the proportion of workers who return to work is smaller and the duration of work related disability much longer. ${ }^{5-9}$ These studies included a proportion of workers with previous episodes of back pain who often entered the study after many weeks or months of back pain after courses of treatment. We postulated that some insights into the natural history of rehabilitation, and hence into approaches for tertiary prevention, could be gained from the study of a cohort of workers homogeneous with respect to back pain history, planned treatment, and delay between the accident and the beginning of rehabilitative treatment.

We carried out a treatment inception cohort study among workers with a first compensated episode of back pain who entered the cohort at the beginning of rehabilitation treatment soon after the work accident. The objective of the study was to find which factors measured at baseline and during treatment influence the time it takes to return to work.

\section{Methods}

STUDY POPULATION

Between November 1988 and May 1992, 829 workers with a compensated low back pain presented at two designated centres of the Québec Health and Safety Commission in Montréal for rehabilitative treatment. The government agency awards compensation on the basis of an accident report filled out by the worker and a medical examination by an independent physician. This may ask for a referral to a rehabilitation centre; if referral is approved by the Québec Health and Safety Commission, the patient and the treating physician choose a treatment centre which 
must be accredited by the Québec Health and Safety Commission.

At eligibility screening workers who reported an episode of back pain in the past five years which kept them away from work for more than one day or bedridden for two consecutive days were excluded if they were not working at that time.

There were 402 eligible subjects (48\%); among those $305(76 \%)$ agreed and gave written informed consent to participate in the study. We were able to get some data for 46 of the 97 subjects who did not participate in the study; their mean age was 36.7 years, $30.4 \%$ were women, $24 \%$ worked in the public sector, and none had more than a secondary education. In comparison, the mean age of the participating sample was 34.9 years, $26 \cdot 2 \%$ were women, $30 \%$ worked in the public sector, and $12 \%$ had a college education or more.

\section{STUDY PROCEDURE AND MEASUREMENTS}

Study participants were interviewed at entry into the study for sociodemographic characteristics as well as smoking habits. This questionnaire also included information on work environment such as job title, duration of employment, type (public $v$ private) and size of industry, status of employment-for example, full time-and salary insurance. Also, a detailed questionnaire was given which included questions on the physical characteristics of work (nature of physical effort), work conditions (piecework, repetitiveness, possibility of taking unscheduled breaks), and work satisfaction (feeling towards work and work conditions). To evaluate the work conditions, the faces scale, ${ }^{10}$ which is a seven point scale consisting of stylised faces, was used. Preliminary screening analyses were carried out for each variable from the work questionnaire. The variables kept for further analysis showed some differences between those who returned to work and those who did not. Those variables, which in our judgment best captured the main sections of the questionnaire and had been reported with some frequency in previous studies were used in the analysis. The physiotherapist interviewer asked about the circumstances relating to the accident and measured the amplitude of flexion at time of entry into the study with a goniometer. These measurements were repeated after three or four days of treatment. Scores for the second measurement were defined as good if they were in the top $15 \%$ of the range of measurements. Treatment was convential (massages, heat, exercises, lumbar traction, etc); discharge was decided by the treating physician. After discharge, workers were followed up for return to work as well as for first relapse, but relapse will not be covered in this paper.

Medical records were reviewed after discharge to extract information on diagnosis, and symptoms at entry into the treatment and during its course. Diagnoses were grouped in three categories by the physician: the first ( 263 subjects) included sprains and strains of the sacroiliac region and of other parts of the back (international classification of diseases (ICD9) 846 and 847) and back pain (724); the second (27 subjects) included intervertebral disc disorders (722), and the third (11 workers) included other diagnoses such spondylosis of unspecified type (721.9), disorders of muscles, other acquired deformity (738), other congenital musculoskeletal anomalies (756.9), and simple lumbar fracture without mention of spinal cord injury $(805 \cdot 4)$. Symptoms were reported in the medical record so it was possible to determine whether the patient had the following symptoms at entry or any time during the course of treatment: pain radiating in each leg to the buttock, to the knees, the heel, or the toes; neurological symptoms such as sensory deficit, muscular weakness, and slower reflexes; and limitation in the amplitude of movements as found by the physician (information on the procedure to determine amplitude of movement during the examination was not collected). In the analysis, the variables pain radiating and neurological symptoms were defined as positive if present in any of the categories and negative otherwise.

\section{STATISTICAL ANALYSIS}

Return to work and duration of time off work, between the beginning of treatment and return to work, were the outcomes of interest. A Kaplan-Meier survival curve was estimated to describe the probability of not returning to work in relation to time since beginning of treatment. A Cox's proportional hazards regression model was used to assess the independent contribution of each variable to the probability of returning to work. Rate ratios (RRs) and 95\% confidence intervals (95\% CIs) were estimated for each variable.

The strategy of analysis was to compare ${ }^{11}$ the baseline model and a model including a single variable with the $-2 \log$ likelihood statistic which measures the extent to which data are fitted by a particular model. All variables contributing significantly ( $P$ value $<0 \cdot 10)$ to the fit were then put into a single model. With the same statistic, nested models were compared where one variable at a time was taken out. For this approach, 295 subjects with complete information were used. The best model was thus chosen on the basis of the contribution of the variables to the fit. Then, each variable which was not significant in the univariate analyses was added one at a time to the chosen model to find if it then made a significant contribution. None of them did. The final model included 291 subjects and the inclusion criterion remained $P=0.10$ because of the descriptive nature of the study. The proportional hazards assumption of the final Cox's model was tested by entering time dependent variables in the model. Flexion amplitude was only marginally significant (based on the log likelihood test) at $P=0.07$ and was left in the model. However, the ratio of the hazard functions for those with and without radiating pain during treatment was not constant. To account for this, an analysis was carried out stratified on this variable.

With the final model, we estimated a prog- 


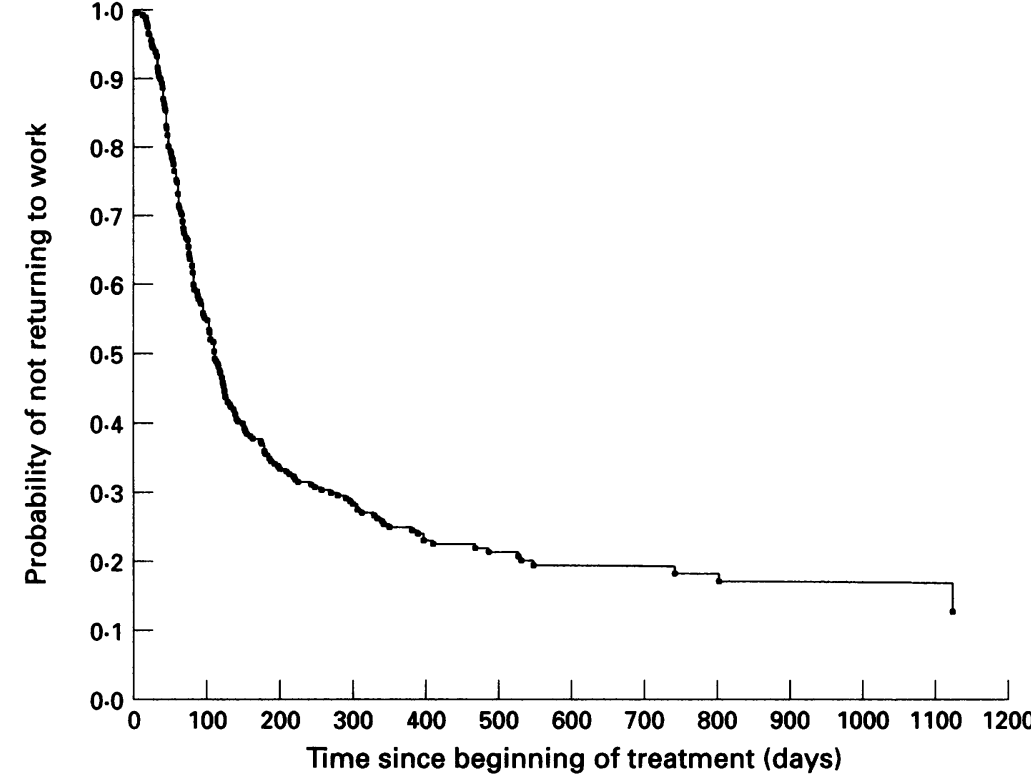

Figure 1 Probability of returning to work by time since the beginning of treatment among all study subjects.

nostic index (PI) for each worker

$$
P I_{i}=\exp \left(b_{1}\left(z_{1 i}-z_{1}\right)+\ldots+b_{p}\left(z_{p i}-z_{p}\right)\right),
$$

where $b_{1}, \ldots b_{p}$ are unknown regression coefficients estimated by the model and $z_{1} \ldots z_{p}$ are the covariates. The PI index can be interpreted as the predicted return to work for a worker at given levels of prognostic factors relative to a worker who would have each variable at the mean level for the cohort. The prognostic index and the estimated baseline hazard function are combined to estimate the survivor function (probability of not returning to work) at different times after the beginning of treatment.

$$
S(t, z)=\exp \left(-P I H_{0}(t)\right),
$$

where $H_{0}(t)=\int h_{0}(t) d t$ is called the cumula-

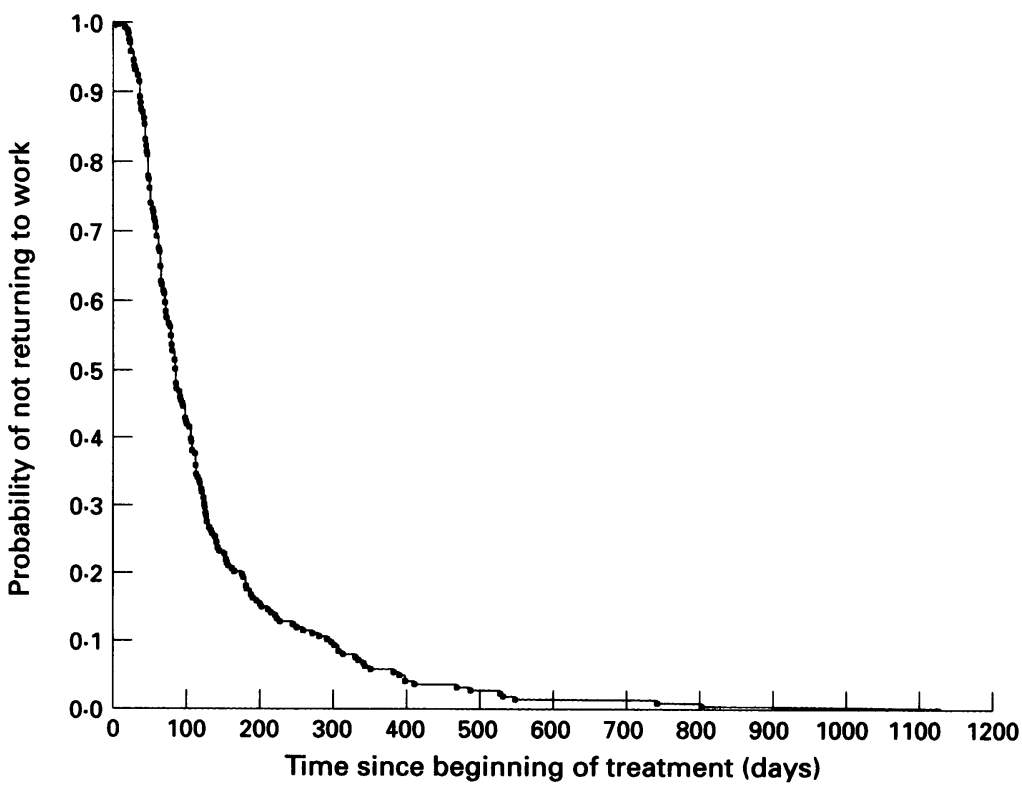

Figure 2 Probability of returming to work by time since the beginning of treatment among subjects who returned to work. tive baseline hazard. This may be re-expressed as:

$$
\mathrm{S}(\mathrm{t}, \mathrm{z})=\left(\mathrm{S}_{0}(\mathrm{t})\right)^{\mathrm{PI}},
$$

where $S_{0}(t)=S(t, 0)$ is the baseline survivor function estimated from the cohort at different times. A separate function was estimated for those with and without radiating pain during treatment. The survivor functions at 60,90 , and 120 days are presented for two hypothetical patient profiles.

\section{Results}

BASELINE CHARACTERISTICS

Mean (SD) age of the group was 34.9 (11.5) years with a range from 18 to 63 . There were $225(73.5 \%)$ men in the study and $80(26.3 \%)$ women. The work entailed physical effort for $290(95 \cdot 7 \%)$ workers. Diagnosis was back sprain, strain, or pain for $263(87 \%)$ cases.

Job titles and industrial groups were classified according to the Canadian classification of occupations and industries. ${ }^{1213}$ The distribution of workers according to occupation was: material handling and related occupations $(17 \cdot 7 \%)$; service $(15 \cdot 4 \%)$; product fabricating, assembling, and repairing $(11 \cdot 1 \%)$; transport equipment operating $(10 \cdot 1 \%)$; machining and related occupations $(9.5 \%)$; occupations in health (7.5\%); clerical and related occupations $(6.5 \%)$; processing $(6.3 \%)$; construction trade $(6 \cdot 2 \%)$; and others $(9 \cdot 2 \%)$. The industries from which these workers came were: manufacturing $(30.8 \%)$; transportation and storage $(15 \cdot 7 \%)$; health and welfare services $(11 \cdot 1 \%)$; retail trade $(10 \cdot 1 \%)$; wholesale trade $(7 \cdot 5 \%)$; construction industry $(6.2 \%)$; communication, electric power, gas, and water utilities $(4 \cdot 2 \%)$; and others $(19 \cdot 3 \%)$.

TIME TO RETURN TO WORK

Out of the 305 workers in the study, 230 $(75.4 \%)$ returned to work; $20(6.5 \%)$ had not returned at the end of the study; 20 retired, went into vocational training, or returned to education; and $35(11.4 \%)$ were lost to follow up. In each of these groups, mean (SD) duration of follow up in days was $126.9(136.9)$, $766 \cdot 1(286 \cdot 7), 448 \cdot 2(225 \cdot 2)$, and $273 \cdot 3$ $(241 \cdot 7)$, respectively. Minimum and maximum follow up times were four and 1127 days among those returning to work, 293 and 1228 days among those not returning, 69 and 880 among those who retired, went into vocational training or education, and 14 and 892 among those lost to follow up. Among those lost to follow up, over $50 \%$ were followed up for between seven and 29 months. Figure 1 shows the probability of not returning to work in the entire cohort according to time since the beginning of treatment. After 112 days, $50 \%$ of workers had not returned to work. A similar curve (fig 2) includes only those who returned to work; after 82 days, $50 \%$ had not returned.

\section{PROGNOSTIC FACTORS}

Table 1 shows that age was a marginally significant prognostic variable (log likelihood $\chi^{2}, P$ 
Table 1 Univariate hazard ratio (RR) and $95 \%$ CIs for return to work according to sociodemographic factors

\begin{tabular}{|c|c|c|c|}
\hline Factor & Subjects $n$ & $R R(95 \% C I)$ & $P$ value* \\
\hline \multicolumn{3}{|l|}{ Sex: } & \multirow[t]{3}{*}{$0 \cdot 32$} \\
\hline Men & 225 & $1.00-$ & \\
\hline Women & 80 & $1.15(0.86-1.54)$ & \\
\hline \multicolumn{3}{|l|}{ Marital status: } & \multirow[t]{3}{*}{$0 \cdot 36$} \\
\hline Alone, widow, divorced & 139 & $1.00-$ & \\
\hline Living as a couple & 165 & $1 \cdot 12(0 \cdot 86-1 \cdot 46)$ & \\
\hline \multicolumn{3}{|l|}{ Age $(y):$} & \multirow[t]{3}{*}{0.06} \\
\hline$>30$ & $\begin{array}{r}173 \\
32\end{array}$ & $1.00-$ & \\
\hline$\underset{21-30}{\leqslant}$ & $\begin{array}{r}32 \\
100\end{array}$ & $\begin{array}{l}1.25(0.80-1.95) \\
1.39(1.04-1.84)\end{array}$ & \\
\hline \multicolumn{3}{|l|}{ Schooling: } & \multirow[t]{5}{*}{$0 \cdot 11$} \\
\hline Elementary & 51 & $1 \cdot 00-$ & \\
\hline Secondary & 215 & $1.32(0.92-1.90)$ & \\
\hline College & 28 & $1.91(1.13-3.23)$ & \\
\hline University & 9 & $1.48(0.65-3 \cdot 35)$ & \\
\hline \multicolumn{3}{|l|}{ Smoking: } & \multirow[t]{3}{*}{0.06} \\
\hline Yes & 184 & $1.00-$ & \\
\hline No & 121 & $1.28(0.99-1.67)$ & \\
\hline
\end{tabular}

${ }^{\star} \mathrm{P}$ value for the likelihood ratio test statistic comparing the null model with one including the selected variable.

Table 2 Univariate hazard ratio (RR) and 95\% CIs for return to work according to work environment characteristics

\begin{tabular}{|c|c|c|c|}
\hline Factor & Subjects $n$ & $R R(95 \% C I)$ & $P$ value ${ }^{\star}$ \\
\hline \multicolumn{3}{|l|}{ Type of industry: } & \multirow[t]{3}{*}{0.005} \\
\hline Private & 209 & $1.00-$ & \\
\hline Public & 90 & $1.50(1.13-1.98)$ & \\
\hline \multicolumn{3}{|l|}{ Size of industry (employees, $\mathrm{n}$ ): } & \multirow[t]{3}{*}{0.005} \\
\hline $\begin{array}{l}<100 \\
\geq 100\end{array}$ & 116 & $1.00-$ & \\
\hline \multirow{2}{*}{\multicolumn{3}{|c|}{$\begin{array}{l}\text { Duration of employment } \\
\text { in the industry (months): }\end{array}$}} & \\
\hline & & & \multirow[t]{2}{*}{0.006} \\
\hline $\begin{array}{l}\leqslant 24 \\
>24\end{array}$ & $\begin{array}{l}137 \\
168\end{array}$ & $\begin{array}{l}1.00- \\
1 \cdot 44(1 \cdot 10-1 \cdot 88)\end{array}$ & \\
\hline \multicolumn{3}{|l|}{ Status of employment: } & \multirow[t]{4}{*}{0.05} \\
\hline Occasional & 25 & $1.00-$ & \\
\hline Part time & 16 & $2.02(0.96-4.24)$ & \\
\hline Full time & 263 & $1.81(1.05-3.12)$ & \\
\hline \multicolumn{3}{|l|}{ Salary insurance: } & \multirow[t]{3}{*}{0.002} \\
\hline No & 126 & $1.00-$ & \\
\hline Yes & 179 & $1 \cdot 51(1 \cdot 15-2 \cdot 00)$ & \\
\hline
\end{tabular}

${ }^{\star} \mathrm{P}$ value for the likelihood ratio test statistic comparing the null model with one including the selected variable.

Table 3 Univariate hazard ratio ( $R R$ ) and $95 \%$ CIs for return to work according to physical characteristics of work, work conditions, and satisfaction

\begin{tabular}{|c|c|c|c|}
\hline Factor & Subjects $n$ & $R R(95 \% C I)$ & $P$ value ${ }^{*}$ \\
\hline \multicolumn{3}{|l|}{ Work entails moving, } & 0.70 \\
\hline Yes & 282 & $1.00-$ & \\
\hline \multirow{2}{*}{\multicolumn{4}{|c|}{ Work entails major }} \\
\hline & & & \\
\hline physical efforts: & & & 0.21 \\
\hline Regularly & 154 & $1.00-$ & \\
\hline Occasionally & 108 & $1.08(1.81-1.43)$ & \\
\hline No & 43 & $1.40(0.97-2.03)$ & \\
\hline \multicolumn{3}{|l|}{ Piecework: } & 0.65 \\
\hline $\begin{array}{l}\text { Yes } \\
\text { No }\end{array}$ & $\begin{array}{r}81 \\
224\end{array}$ & $1.00-(0.79-1.43)$ & \\
\hline \multicolumn{3}{|l|}{ Repetitive work: } & 0.004 \\
\hline Very & 115 & $1.00-$ & \\
\hline Somewhat & 53 & $1.72(1.20-2.49)$ & \\
\hline Not much & 28 & $1.97(1.26-3.08)$ & \\
\hline No & 99 & $1.18(0.86-1.62)$ & \\
\hline \multicolumn{3}{|l|}{ Can take breaks unscheduled: } & 0.02 \\
\hline No & 91 & $1.00-$ & \\
\hline Yes & 112 & $1.39(1.04-1.86)$ & \\
\hline \multicolumn{4}{|l|}{ Feeling towards work } \\
\hline (faces scale): & & & 0.25 \\
\hline Sad to very sad & 37 & $1.00-$ & \\
\hline Neutral & 32 & $1 \cdot 30(0 \cdot 76-2 \cdot 22)$ & \\
\hline Happy to very happy & 236 & $0.91(0.61-1.36)$ & \\
\hline \\
\hline $\begin{array}{l}\text { conditions (faces scale): } \\
\text { Sad to very sad }\end{array}$ & & & 0.63 \\
\hline $\begin{array}{l}\text { Sad to very sad } \\
\text { Neutral }\end{array}$ & $\begin{array}{l}96 \\
41\end{array}$ & $\begin{array}{l}1.00- \\
1.23(0.80-1.87)\end{array}$ & \\
\hline Happy to very happy & 168 & $1.07(0.80-1.44)$ & \\
\hline
\end{tabular}

*P value for the likelihood ratio test statistic comparing the null model with one including the selected variable.
$=0.06) ;$ in comparison with older workers ( $>30$ years), those $\leqslant 20$ years of age had a $25 \%$ greater chance of returning to work and those between 21 and 30 years of age a 39\% greater chance. Non-smokers had a marginally significantly increased chance of returning to work (RR (95\% CI) $1.28(0.99$ to 1.67$))$. Sex, marital status, and level of schooling did not contribute significantly to the probability of return to work. All the variables grouped under work environment were independent predictors of return to work (table 2); working for a public $v$ a private industry was associated with an increased probability of return as well as working in a larger industry, having worked longer in the industry, being a full time employee $v$ being an occasional employee, and having salary insurance at work. Table 3 shows results associated with the physical characteristics of work, work conditions, and satisfaction. Work which was less than very repetitive was associated with an increased probability of return to work as was the possibility of taking unscheduled breaks during work. Neither the physical characteristics of work nor satisfaction made an independent contribution to the probability of return to work.

Among the clinical characteristics ascertained (table 4), the nature of the accident was marginally significant ( $\log$ likelihood $\chi^{2}, P=$ $0 \cdot 07$ ). Only for this variable are results presented in such a way that the RRs are below the null value of one-for example, if back pain was reported to be the result of a crash, the probability of returning to work was almost $50 \%$ lower than if the accident resulted from effort or a movement. A diagnosis of sprain or pain in comparison with a disorder of an intervetebral disc, a good flexion angle three or four days into treatment, the absence of radiating pain at baseline and during treatment, the absence of neurological symptoms and of limitation in amplitude of movement (reported by the physician) during treatment, and a shorter time interval between the accident and the beginning of treatment all significantly increased the probability of return to work. For example, a diagnosis of sprain or pain in comparison with one of disc disorder increased the probability of return to work by $242 \%$, the absence of radiating pain during treatment by $208 \%$, a good flexion angle by $67 \%$, and the absence of neurological symptoms during treatment by $79 \%$.

In the final multivariate model, stratified for radiating pain during treatment, the following variables were independent prognostic factors favouring a return to work (table 5): younger age, a diagnosis of pain or sprain, a shorter interval between the accident and the beginning of treatment, a good flexion at the beginning of treatment, absence of neurological symptoms during treatment, longer duration of employment in the industry, working for a public industry rather than a private one, and the possibility to take unscheduled breaks.

The probabilities of not returning to work were estimated for two hypothetical workers (table 6); they were both between 21 and 30 
Table 4 Univariate hazard ratio (RR) and 95\% CIs for return to work according to clinical characteristics at baseline and during treatment

\begin{tabular}{|c|c|c|c|}
\hline Factor & Subjects $n$ & $R R(95 \% C I)$ & $P$ value ${ }^{\star}$ \\
\hline \multicolumn{3}{|l|}{ Nature of the accident: } & \multirow[t]{6}{*}{0.07} \\
\hline Effort or movement & 214 & $1.00-$ & \\
\hline Fall & 40 & $0.88(0.60-1 \cdot 29)$ & \\
\hline Crash & 16 & $0.48(0.24-0.99)$ & \\
\hline Slip & 13 & $0.88(0.60-1.29)$ & \\
\hline Other & 22 & $0.62(0.36-1.05)$ & \\
\hline \multicolumn{3}{|l|}{ Diagnostic category: } & \multirow[t]{4}{*}{0.001} \\
\hline Disc disorder & 27 & $1.00-$ & \\
\hline Back sprain or pain & 263 & $2 \cdot 42(1 \cdot 40-4 \cdot 17)$ & \\
\hline Other & 11 & $2.00(0.80-4.99)$ & \\
\hline \multicolumn{3}{|l|}{ Measured flexion at baseline: } & \multirow[t]{4}{*}{0.02} \\
\hline Poor to low & 236 & $1.00-$ & \\
\hline Good & 44 & $1.67(1 \cdot 17-2 \cdot 38)$ & \\
\hline Unknown & 25 & $1.31(0.82-2.08)$ & \\
\hline \multicolumn{3}{|l|}{ Pain radiates at baseline: } & \multirow[t]{3}{*}{0.02} \\
\hline Yes & 80 & $1.00-$ & \\
\hline \multirow{2}{*}{\multicolumn{4}{|c|}{ Limitation in amplitude of }} \\
\hline & & & \\
\hline movement at baseline: & & & \multirow[t]{3}{*}{$0 \cdot 11$} \\
\hline Yes & 99 & $1 \cdot 00-$ & \\
\hline No & 196 & $1.25(0.94-1.66)$ & \\
\hline \multicolumn{4}{|l|}{ Neurological symptoms } \\
\hline $\begin{array}{l}\text { at baseline: } \\
\text { Yes }\end{array}$ & 14 & $1.00-$ & \multirow[t]{2}{*}{$0 \cdot 30$} \\
\hline No & 290 & $1.37(0.72-2.59)$ & \\
\hline \multirow{2}{*}{\multicolumn{3}{|c|}{ Pain radiates during }} & \multirow{4}{*}{0.0000} \\
\hline & & & \\
\hline Yes & 136 & $1.00-$ & \\
\hline No & 167 & $2.08(1.59-2 \cdot 72)$ & \\
\hline \multirow{2}{*}{\multicolumn{3}{|c|}{ Limitation in amplitude of }} & \multirow{4}{*}{0.0059} \\
\hline & & & \\
\hline Yes & 274 & $1.00-$ & \\
\hline No & 28 & $1.86(1 \cdot 23-2 \cdot 81)$ & \\
\hline \multirow{2}{*}{\multicolumn{3}{|c|}{$\begin{array}{l}\text { Neurological symptoms } \\
\text { during treatment: }\end{array}$}} & \multirow{4}{*}{0.0002} \\
\hline & & & \\
\hline Yes & 79 & $1.00-$ & \\
\hline No & 224 & $1.79(1.30-2 \cdot 45)$ & \\
\hline \multirow{2}{*}{\multicolumn{3}{|c|}{$\begin{array}{l}\text { Other reported medical } \\
\text { problems: }\end{array}$}} & \multirow{4}{*}{0.43} \\
\hline & & & \\
\hline Yes & 59 & $1.00-$ & \\
\hline No & 245 & $1 \cdot 14(0.81-1 \cdot 59)$ & \\
\hline \multicolumn{3}{|l|}{ Previous back pain episode: } & \multirow[t]{3}{*}{0.40} \\
\hline No & 262 & $1.00-$ & \\
\hline Yes & 43 & $1 \cdot 17(0.81-1 \cdot 69)$ & \\
\hline Body mass index (percentile): & & & 0.57 \\
\hline$>75$ th & 74 & $1.00-$ & \\
\hline $\begin{array}{l}\leqslant 75 \text { th } \\
\text { Duration between accident and }\end{array}$ & 224 & $1.09(0.80-1.48)$ & \\
\hline $\begin{array}{l}\text { Duration between accident and } \\
\text { beginning of treatment (days): }\end{array}$ & & & 0.04 \\
\hline$>30$ & 86 & $1.00-$ & \\
\hline$\leqslant 30$ & 219 & $1.34(1.00-1.81)$ & \\
\hline
\end{tabular}

*P value for the likelihood ratio test statistic comparing the null model with one including the selected variable.

Table 5 Multivariate Cox's regression model (stratified for radiating pain during treatment) of factors measured at baseline and during treatment affecting return to work

\begin{tabular}{|c|c|c|c|}
\hline Factor & Subjects $n$ & $R R(95 \% C I)$ & $\begin{array}{l}\text { Wald test } \\
P \text { value }\end{array}$ \\
\hline \multicolumn{4}{|l|}{ Age $(y)$ : } \\
\hline$>30$ & 164 & $1.00-$ & \\
\hline$\leqslant 20$ & 29 & $1.44(0.85-2 \cdot 43)$ & $0 \cdot 16$ \\
\hline $21-30$ & 98 & $1.43(1.04-1.98)$ & 0.02 \\
\hline \multicolumn{4}{|l|}{ Diagnosis: } \\
\hline Disc disorder & 25 & $1.00-$ & \\
\hline Sprain or pain & 225 & $2 \cdot 20(1 \cdot 23-3 \cdot 91)$ & 0.007 \\
\hline Other & 11 & $1.58(0.61-4.09)$ & $0 \cdot 33$ \\
\hline \multicolumn{4}{|c|}{$\begin{array}{l}\text { Duration (days) between accident } \\
\text { and beginning of treatment: }\end{array}$} \\
\hline$>30$ & 83 & $1.00-$ & \\
\hline$\leqslant 30$ & 208 & $1.30(0.96-1.77)$ & 0.08 \\
\hline \multicolumn{4}{|c|}{ Measured flexion at baseline: } \\
\hline Poor to low & 225 & $1.00-$ & \\
\hline Good & 42 & $1 \cdot 52(1 \cdot 04-2 \cdot 23)$ & 0.03 \\
\hline Unknown & 24 & $1.55(0.94-2.54)$ & 0.08 \\
\hline \multicolumn{4}{|c|}{ Neurological signs during treatment: } \\
\hline Yes & 72 & $1.00-$ & \\
\hline No & 219 & $1.40(0 \cdot 98-2 \cdot 00)$ & 0.059 \\
\hline \multicolumn{4}{|l|}{ Type of enterprise: } \\
\hline Private & 203 & $1.00-$ & \\
\hline Public & 88 & $1 \cdot 63(1 \cdot 21-2 \cdot 19)$ & 0.001 \\
\hline \multicolumn{4}{|c|}{$\begin{array}{l}\text { Duration of employment in this } \\
\text { industry (months): }\end{array}$} \\
\hline$\leqslant 24$ & 131 & $1.00-$ & \\
\hline$>24$ & 160 & $1.49(1 \cdot 10-2 \cdot 03)$ & 0.009 \\
\hline \multicolumn{4}{|c|}{ Can take unscheduled breaks: } \\
\hline No & 85 & $1.00-$ & \\
\hline Yes & 206 & $1.45(1.06-1.97)$ & 0.01 \\
\hline
\end{tabular}

years of age, worked in the public sector, had 24 months or less of employment in the industry where the accident occurred, and could take unscheduled breaks. However, subject B
Table 6 Estimated probabilities of not returning to work based on the final multivariate model ${ }^{*}$

\begin{tabular}{|c|c|c|c|c|}
\hline & \multicolumn{4}{|c|}{ Pain radiating during treatment } \\
\hline & \multicolumn{2}{|c|}{ Patient $A$} & \multicolumn{2}{|c|}{ Patient B } \\
\hline & Yes & No & Yes & No \\
\hline $\begin{array}{l}\text { Number of days: } \\
60 \\
90 \\
120\end{array}$ & $\begin{array}{l}0.72 \\
0.52 \\
0 \cdot 36\end{array}$ & $\begin{array}{l}0.30 \\
0.08 \\
0.03\end{array}$ & $\begin{array}{l}0.95 \\
0.90 \\
0.84\end{array}$ & $\begin{array}{l}0.82 \\
0.67 \\
0.58\end{array}$ \\
\hline
\end{tabular}

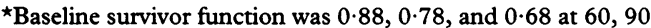
and 120 days, respectively, among those with radiating pain during treatment, and $0.65,0.41$, and $0 \cdot 29$, respectively, among those without such symptoms. The prognostic index was 0.99 for patient $A$ and -0.82 for patient $B$.

had a less favourable profile because he had a diagnosis of intervertebral disc disorder, waited more than 30 days to start treatment, had poor to low flexion at baseline, and neurological symptoms during treatment. Patient A had a diagnosis of sprain or pain, waited $<30$ days for treatment, had good flexion at baseline, and no neurological symptoms during treatment. As the survivor functions were different according to presence or absence of radiating pain during treatment, the probabilities for each subject (A and B) are presented according to presence or absence of this symptom. At each chosen time after the beginning of treatment, subject A had substantially lower probabilities of not returning to work than did subject $B$, and this was even more notable if he or she did not have radiating pain during treatment.

\section{Discussion}

This study is one of the largest published to date on workers with back pain individually followed up and the only one that we know of to include a group of workers homogeneous for their histories of back pain. Also, this is a treatment inception cohort in the sense that all study participants were included at the beginning of conventional rehabilitative treatment.

Some workers were followed up for up to 40 months. The survival curve (probability of not returning to work) started to plateau around 200 days ( 6.5 months), when there were still $35 \%$ of subjects who had not returned to work. This proportion is in sharp contrast with administrative statistics that include all compensated workers (even those not necessitating treatment) where $74 \%$ had returned after one month, an additional $9 \%$ after three months, and $4.3 \%$ were still off work after a year. ${ }^{4}$ Our data contrast even more with data from a small cohort of about 100 subjects (75 employed and 30 unemployed) with pain lasting less than 72 hours and who presented at the office of participating physicians in a recent study carried out in France. ${ }^{5}$ From a figure provided in that article, we estimated that $80 \%$ of compensated workers had returned to work within two weeks after entry into the study. On the other hand, our data compare better with other cohort studies where subjects went into treatment; however, comparisons remain limited due to the considerable heterogeneity between studied groups. Lehmann et $a l^{6}$ reported an $83 \%$ return to 
work rate after seven months in a cohort of 60 workers where losses to follow up (8.3\%) were excluded from the analysis and workers at entry had been away from work between two and six months. Lancourt and Kettelhut ${ }^{8}$ followed up 134 workers out of 160 included in the study ( $16 \%$ loss) for six months; these were patients with acute injury as well as chronic low back pain referred from orthopedic and rehabilitative clinics. Among those successfully followed up, $33 \%$ had returned to work at six months. Gallagher et $a l^{8}$ included 92 patients attending a university low back pain clinic who had not asked for social security disability and 77 who had. At six months, $11.3 \%$ were lost to follow up. About $50 \%$ had been unemployed for more than seven months at entry into the study. In the first group, $41.4 \%$ had returned to work at six months, whereas among patients who had asked for social security benefits, $15.9 \%$ had returned.

On the whole, these data suggest prudence when proposing figures about the proportion returning to work according to time; the notable heterogeneity of studied groups is associated with widely different proportions. However, among those who go into rehabilitative treatment and who do return to work, time to return is generally long. It was so in our cohort even though the studied sample included only first epidodes of back pain and mostly short durations before entering treatment.

As to the absolute proportion of workers not returning to work (regardless of time), this study is informative because of its long follow up. We are sure that $6.5 \%$ did not return to work at the end of the study period; a similar percentage will decide to retire, go into vocational training, or return to education after an episode of back pain. We are not aware that other studies have reported these outcomes as such. Finally, among the $35(11.4 \%)$ workers lost to follow up, we speculate that those followed up for seven months or more (18 subjects) were unlikely to return to work; these losses were generally not because we could not trace the workers but because at that point they refused to talk to us. It was perhaps more difficult for them to admit that they were not contemplating return to work. A first episode of back pain which results in possibly $>12 \%$ of workers not returning to work (assuming that 18 of the 35 workers lost to follow up do not return to work) and an additional $6 \%$ retiring or leaving work to retrain has a potentially outstanding effect on the workforce in a society. We can only speculate in this study about the effect of the status of the economy on return to work; however, it is worth mentioning that half the study was carried out during a strong economic recession in Canada.

The final multivariate model for the two hypothetical patient profiles indicated that three types of variables influence return to work; physical variables, clinical variables such as age, diagnosis, delay before the start of treatment, measured flexion, and neurological symptoms, and the effect of radiating pain during treatment. Social variables (working in a public industry and duration of employment) were also influential, as well as work conditions (ability to take a break). Comparison with previous cohort studies is difficult not only because inclusion criteria were different but also because the studied variables were not identical. Despite that, some prognostic variables identified in this study were similarly predictive in others. Cheadle et al ${ }^{14}$ used administrative databases in Washington State to include close to 29000 compensated workers with claims involving at least four days of time lost. The sample included $34 \%$ of workers with back sprain; other causes were fracture, sprains, carpal tunnel syndrome, and others. Analysis was carried out with a Cox's regression analysis. Partly in agreement with the present study, age of workers, firm size, and government ownership of the firm compared with private ownership were significant contributors to the probablilty of return to work. Although not assessing prognostic factors in her study, Tate ${ }^{15}$ briefly reviews a few articles from the legal and business literature on factors which have an impact on return to work; she mentions that workers with a longer history of employment, who are younger, better educated, and who have discretion in how work is done have better chances of returning to work. Comparisons with other published cohort studies are more difficult as in these studies, return to work was assessed at six or three months after entry into the study, and only among those not lost to follow up..$^{5-8}$

We have not measured a psychological profile, but findings from previous studies have not been consistent. ${ }^{16}$ The results of such evaluations among chronically affected subjects are unlikely to help in untangling what personality traits at the start of disease, if any, will influence recovery. Personal psychological characteristics may interfere in this problem; however, it is probable that in most studies the condition itself and its consequences affected the measurement of personality traits in such a way as to make the interpretation of results difficult.

The final statistical model in this study can be used with comparable populations to estimate the probability of not returning to work at specific times after the beginning of treatment. Despite its statistical and face validity, it most certainly does not capture the entire clinical reality, and has measurement errors which decrease the precision of estimates. It shows that as for most diseases, clinical factors are prognostic. Also, that there is a strong social factor influencing disability from back pain. It is likely (based on our empirical knowledge in this community) that public industries are larger, have more job options to accomodate workers who have suffered back pain, and stronger union protection. Duration of work in the industry is probably confounded by worker redundancies which will usually protect senior workers. The junior employee who does not (or cannot) return to work in the same industry after a first episode 
of back pain will eventually seek a job at another industry; however, as employers will seek information on history of accidents, this episode may be the beginning of the unemployment spiral. This raises the issue of reinstatement programmes which is beyond the scope of this paper but needs to be considered in view of the results in the present study. The ability to take a break at work which was associated with a $45 \%$ increase in chance of returning to work could indicate physical as well as psychological work conditions. Because piecework was not a predictor of return to work, we tend to interpret the ability to take a break as a factor which is more related to decision latitude than to physical exertion, as it allows some self regulation of the psychological demand. There have been studies indicating an increased risk of cardiovascular disease ${ }^{1718}$ and of adverse pregnancy outcomes $^{19}$ in relation to high psychological demand and low decision latitude at work.

In conclusion, this study has contributed useful descriptive data on the survival curve for return to work; it has used an appropriate method of analysis accounting for the losses to follow up in the analysis, and has confirmed that return to work is, as expected, influenced by disease and host characteristics, but also by factors which are social and conjectural and by work conditions which could be related to stress.

This project was supported by a grant from the Institut de Recherche en Santé et Sécurité du Travail du Québec. We are indebted to Luce Duval (Hôpital Champlain de Verdun) and Diane Milot for data collection.
1 Nachemson AL. Newest knowledge of low back pain. A critical look. Clin Orthop 1992;279:8-20.

2 Frymoyer JW, Cats-Baril WL. An overview of the incidences and costs of low back pain. Orthop Clin North Am 1991;22:263-71.

3 Nachemson A. Chronic pain. The end of the welfare state. Quality of Life Research 1994;3(suppl 1):S11-3.

4 Abenahaim L, Suissa S. Importance and economic burden of occupational back pain: a study of 2500 cases representative of Quebec. $\mathcal{F}$ Occup Med 1987;29:670-4.

5 Coste J, Delecoeuillerie G, Cohen de Lara A, Le Parc JM, Paolaggi JB. Clinical course and prognostic factors in acute low back pain: an inception cohort study in primary acute low back pain: an inception coho

6 Lehmann TR, Spratt KF, Lehmann KK. Predicting longterm disability in low back injured workers presenting to a term disability in low back injured worke

7 Lancourt J, Kettelhut M. Predicting return to work for lower back pain patients receiving worker's compensation. Spine 1992;6:629-40.

8 Gallagher RM, Rauh V, Haugh LD, Milhous R, Callas $\mathrm{PW}$, Langelier $\mathrm{R}$, et al. Determinants of return-to-work among low back pain patients. Pain 1989;39:55-67.

9 Deyo RA, Diehl AK. Psychosocial predictors of disability with low back pain. $\mathcal{F}$ Rheumatol 1988 ;15:1557-64.

10 McDowell I, Newell C. Measuring health. New York: Oxford University Press. 1987, 213-8.

11 Collett D. Modelling survival data in medical care. London: Chapman and Hall, 1994:80-1.

12 Manpower and Immigration Canada. Canadian classification and dictionnary of occupations-1971. 1971.

13 Ministry of Industry, Trade and Commerce. Dominion Bureau of Statistics. Canadian standard industrial classification manual. 1970 .

14 Cheadle AC, Franklin G, Wolfhagen C, Savarino J, Liu PY, Salley C, et al. Factors influencing the duration of work related disability: a population based study of Washington State Workers' compensation. Am $\mathcal{F}$ Publi Health 1994;84:190-6.

15 Tate DG. Workers' disability and return to work. $A m f$ Phys Med Rehabil 1992;71:92-6.

16 Frymoyer JW. Predicting disability from low back pain. Clin Orthop 1992;279:101-9.

17 Karasek R, Baker D, Marxer F, Ahlbom A, Theorell T. Job decision latitude, job demands, and cardiovascular disease: a prospective study of Swedish men. Am 7 Public ease: a prospective study
Health 1981;71:694-705.

18 Siegrist J, Peter R, Junge A, Cremer P, Seidel D. Low status control, high effort at work and ischemic heart disease: prospective evidence from blue-collar men. $\mathrm{Soc} S \mathrm{Si} \mathrm{Med}$ 1990;31:1127-34

19 Homer CJ, James SA, Siegel E. Work-related psychological stress and risk of preterm, low birthweight delivery. $A m \mathcal{F}$ Public Health 1990;80:173-7. 